\title{
The Traditional Agricultural Tools and Technology used by the Bodos.
}

\author{
Nijra Brahma ${ }^{1}$, Dr. Luke Daimary ${ }^{2}$ \\ I(Ph. D Research Scholar, History Department, Bodoland University, Kokrajhar, BTAD, Assam, India) \\ ${ }^{2}$ (Principal, Udalguri College, Udalguri, BTAD, Assam, India)
}

\begin{abstract}
This study will help in identifying various traditional agricultural tools and technology of the Bodos. Agricultural tools and technology used by the Bodos are economical in conditions of labour, money and time saving. This study will identify and describe both hand and animal drawn agricultural tools and technology used by the Bodos to increase agricultural production. This study was conducted in Simbargaon, Tipkai, and Gossaigaon under Kokrajhar district, in Jhakaragaon under Udalguri district in Bodoland Territorial Area Districts, Assam and in Pacham Satali under Alipurduar district, West Bengal.
\end{abstract}

Keywords: Agricultural implements, Animal drawn tool, hand drawn tools, Traditional tools.

\section{Introduction}

The Bodos are one of the important indigenous tribes of the North East India belonging to the TibetoBurman family of Mongolian race. They belong to a large ethnic group called the Kacharies (Brahma 2011). Dr Suniti Kr. Chatterjee writes, "The Bodos who spread over the whole Brahmaputra valley and North Bengal as well as East Bengal forming a solid block in eastern India and they form one of the main bases of the present day population of this tracts. Judging from the wide range of extension of their language, the Bodos appear to have settled over the entire Brahmaputra valley and extended into North Bengal" (Chatterji 2011). The Bodos are one of the composite parts of the greater Assamese Society forms a major tribe of Kokrajhar district. The Bodos have their own culture, language and religion, although especially in their socio-cultural life, they are not unaffected to external influences (Brahma 2011). The Bodos brought into North-East India, the technique of food production by plant cultivation, and domestication of animals (Bordoloi, Sharma Thakur and Saikia 1987). Agriculture is the main occupation of the Bodos and the Bodos has been mainly earning their livelihood through agriculture since the ancient times. Agriculture as the means of livelihood of the Bodos has also great impact on the Bodo society and their day to day life (Bhyuan 2015). Agricultural practices of the Bodos have been carried out by using hand and animal drawn traditional tools. Traditionally farmers have been using a wide range of tools in their day to day life for agricultural operations (Karthikeyan, et al. 2009). Traditional tools refer to those tools invented in ancient times, and used for a long time, until recently or still being used now to increased agricultural production (Elzubeir 2014). The traditional agricultural tools and technology of the Bodos are mostly made up from local-made materials such as stone, bamboo, wood and iron, by local artisans or even standardized factory-made implements, which are very economical in conditions of labour, money and time saving. The traditional agricultural tools of the Bodos are both used by men and women and there are also tools which are used exclusively by women. Each tool are used in connection with particular function in series of agricultural operations such as land clearance and preparation, plough, sowing, weeding, irrigation, harvesting, post-harvesting operations and transportation.

\section{Objectives}

The main purpose of the study is to gather reliable information about the traditional agricultural tools and technology of the Bodos and to document these traditional tools and technology, as these traditional tools and technology are at the verge of extinction with the coming of modern tools and technology.

\section{Methodology}

This study was carried out by conducting field survey and interviewing people associated with agriculture in various Bodo villages. People having knowledge about traditional agricultural tools and technology were consulted and information was also collected from published works and journals.

\section{Result And Discussion}

Agriculture is still very much regarded as the great industry of the Bodos. The Bodos are selfdependent in nature and they cultivate Sali, ahu and rabi crops largely in the same plot of land. They by their own supply water to their cultivable lands by irrigation, wherever the rainfall is not sufficient. They know all the 
technology of constructing irrigation canals, earthwork embankments for diverting water from river and canal into their paddy fields (Chaudhury 1993).

According to Rev. Sidney Endle, the Kacharis (Bodos) have a highly efficient and very inexpensive "Public Works Department" of their own (Endle 2007).

For the agricultural practices the Bodos have been using a variety of traditional tools, which they make themselves for their convenience, but due to the impact of modernity they started using modern tools and technology along with the traditional ones. The traditional agricultural tools and technology of the Bodos can be identified as the followings:

\subsection{Land Clearance Tools And Technology}

Of all agricultural operations, the most difficult and costly operation is the land clearance. It helps in developing of land with potential agricultural use. The land clearance is done to remove native cover, which includes trees, bushes, roots, stumps, boulders and other obstacles from land surface. The Bodos have many tools and technology for the land clearance purpose:

1.1.1. Ruwa (Axe)

Ruwa the traditional axes used by the Bodos is variety in size, made of soft iron wedge-shaped blade and of wooden handle. The axes are used for cutting shrubs, chopping wood and clearing fields (Fig. 1). It is generally used by male farmers.

\subsubsection{Kodhal (Digging hoe)}

The digging hoe used by the Bodos is called kodhal, it is long-handed cutting hoe with handle made of wood and the working area is made up of iron, of square or rectangular shape. It is used to cut weeds or weeds roots, to bury organic matter (chipped weeds, manure, etc) and also to open the soil up for easy water penetration. Handle is of $65-100 \mathrm{~cm}$ in length and working area has a length of $22 \mathrm{~cm}$ and breadth of $18 \mathrm{~cm}$ (Fig. 2). It is mostly used by male farmers.

\subsubsection{Dangur (Rake) - (a) Dangur/HasnI/Bedha (Local rake) and (b) Lohani Dangur (Factory made-} rake)

The local made dangur (rake) which is still used by the Bodos is long-handed in shape with handle made of wood and bamboo having a horizontal portion and formed by teeth thin or thick depending on usage made of bamboo sticks. Bedha is also a kind of dangur but it is bigger in size in compare to hasni/dangur (Fig. 3 ) and at present the Bodos also use factory-made dangur consists of mild-steel frame and forks of round-iron rod dully worked into points (Fig. 4). This tool is used in taking out trash from seedbed and breaking capillary action in soil after rain to conserve moisture thereby enabling a farmer to carry out tillage and sowing operations over stretch time. It handle is about $164 \mathrm{~cm}$ in length and breadth is about $53 \mathrm{~cm}$. It is generally used by male farmers.

\subsection{Land Preparation Tools And Technology}

The Bodos have variety of traditional agricultural tools and technology which functions with the help of both animals and human for the purposes of tillage and land preparation. This tools and technology are:

\subsubsection{Nangal (Plough)}

In farming the basic operation is tillage and it is done to soften the soil to create favorable conditions for seed placement and plant growth. This is done mainly with an ox-drawn nangal (plough) made of wood, mainly of saal tree (Fig.5).The basic components of the nangal are a shoe, a body, a handle and a beam. The handle of the plough is generally $0.6-1 \mathrm{~m}$ long, $5-7.5 \mathrm{~cm}$ thick and 7.5-12.5 cm wide and is fitted to the body of the plough. The shoe of the plough is variety in shapes and sizes. The share is prepared from mild iron bar generally $0.6-7.5 \mathrm{~m}$ in length and $1.5-2.5 \mathrm{~cm}$ in width and it is fixed to the shoe or body by means of a U-clamp or ring shaped clamp. The share point projects beyond the shoe by $5-7.5 \mathrm{~cm}$. Beams are generally in different in length. This tool is used with a pair of oxen and the depth of plough is $15 \mathrm{~cm}$ mostly. The hitching point can be height-wise and sideways adjusted in order to control the depth of the work and to stabilizes the plough while operation. It is generally operated by male farmers.

\subsubsection{Jungal}

The nangal (plough) cannot operate alone without the support of the jungal, which is made of wood or bamboo, measuring about $1.5 \mathrm{~m}$ (Fig.6). This wooden or bamboo bar is placed on the neck of the pair of oxen while plough horizontally, which is again attached to the dilagon (Fig.7) of the nangal with the help of a rope or lengra dirung (Fig.8) made from jute. It is basically operated by male farmers. 


\subsection{3. $\quad M w i$}

Mwi is made of bamboo, measuring almost $2 \mathrm{~m}$ in length; it's a kind of ladder (Fig.9). It is fixed to the mwi dangur, which is made of split bamboo at the top as well as at the bottom (Fig.10.) with the help of a lengra dirung (rope made of jute) (Fig.8). This tool is used for the purpose of leveling land in order to enable the farmers to prepare the land for tillage and sowing, to improve the irrigation efficiency and this implement is generally operated by male farmers. The length of $m w i$ is $157 \mathrm{~cm}$ with breadth of $44 \mathrm{~cm}$.

\subsubsection{Khodal (Digging hoe)}

Khodal is a digging hoe and it is square or rectangular iron blade and its handle is made of wood or bamboo (Fig.2). Kodal is used for the purpose of moving small or large amount of soil, removing weed control by agitating the surface of the soil around plants, pilling soil around the base of plants, creating narrow furrows and shallow trenches for sowing seeds and planting bulbs, for copping weeds, roots and crop residues. Its handle is about $100 \mathrm{~cm}$ in length, working area of about $22 \mathrm{~cm}$ in length and breadth of about $18 \mathrm{~cm}$. It is used by both male and female.

\subsubsection{Kontha $($ Spud)}

Kontha is a trowel or spud or wimble or a digging tool. It is used for digging, lifting and moving bulk materials, such as soil. Kontha is a hand tool, with handle made of wood or bamboo and working area is made of iron (Fig.11). Its handle is $6 \mathrm{~cm}$ in length, working area has a length of $5 \mathrm{~cm}$ and breadth of $2 \mathrm{~cm}$. It is used by both male and female.

\subsubsection{Gandri or Dangan (Leveller)}

Gandri or Dangan is like hammer in shape but much bigger in size, with handle as well as the working area made of wood (Fig.12). It is used for the purpose of leveling soil by crushing the solid hard soil. Its handle is of $100 \mathrm{~cm}$, working area is of $30 \mathrm{~cm}$ and breadth is of $10 \mathrm{~cm}$. It is generally used by male farmers.

\section{3. $\quad$ Sowing Tools And Technology}

One of the most important steps in agricultural practices is sowing. The traditional tools and technology of the Bodos for the purpose of sowing are:

\subsubsection{Lauthi (Digging stick)}

One of the simplest tools of the Bodos use for the purpose of agriculture is the Lauthi (digging stick). The digging stick is made in such a way that it is pointed at the end to help making holes in the soil in which seeds can be dropped (Fig.13). It is very helpful in planting or spreading seeds in the ground. It is used by both male and female and it is about $1 \mathrm{~m}$ in length.

\subsubsection{Khopri}

Khopri is made of knotted split bamboo and in between the split dried laihulai (some kind of wild leaf) is placed in such a way that it protects the farmers from the rain or the sun and the border areas are tied with the help of raiding or owa jurungto the bamboo which is bend according to the shape of the khopri, farmers wears it on their heads with the support of dirung, which is placed in such a way that it can be tied around the neck of the user. It is used in plantation operation in various shapes and sizes, with muphur khopri larger in length and size in compare to khopri gubai. (Fig.14 \&15). Now a day's farmers also use khopri, where the material between the knotted split bamboos is made of plastic (Fig.16.). The length of the khopri is $114 \mathrm{~cm}$ and its breadth is $67 \mathrm{~cm}$ and it is operated by both male and female.

\subsubsection{Mukha/Kho (Mask)}

Mukha/kho is a mask made of knotted split bamboo, it is like a small basket with a during (rope )made of jute to tie it around the neck of the cows and buffalos (Fig.17.) and it helps in covering the mouth of the cows and buffalos in order to protect the crops from being eaten away by them. Its length is $20 \mathrm{~cm}$ and breadth is also $20 \mathrm{~cm}$.

\subsection{Water-Lifting Tools And Technology}

In order to help farmers' easy access to water, water-lifting tools are used to lift water to a certain height. The Bodos have traditional tools and technology for the purpose of water-lifting which the Bodo people make themselves for their convenience such as: 


\subsubsection{Chili (Water lifter)}

Chili (water lifter) is used by the Bodos to sow water to their paddy fields wherever it is necessary. The Chili is of different sizes, made basically of bamboo. The long handle of the water-lifter is made of bamboo with the working area made of knotted split bamboos and at present the Bodos also make the working area of the water-lifter from plastic as well as (Fig. 18).The handle is of $89 \mathrm{~cm}$ in length, with breadth of $16 \mathrm{~cm}$ and working area measuring almost $55 \mathrm{~cm}$. It is mostly use by male farmers.

\subsection{Harvesting Tools And Technology}

Sickle, knife and cleaver are the basic harvesting tools of the Bodos.

\subsubsection{Kashi (Sickle)}

Kashi (sickle) is a "C" shaped/curved with the view to ease the harvesting operation. The handle of sickle is made up of wood and the working area is made of iron (Fig.19). Working area has $20 \mathrm{~cm}$ length and 3 $\mathrm{cm}$ width. Handle is of $15 \mathrm{~cm}$ height and $5 \mathrm{~cm}$ width. This agricultural tool is used in harvesting crops like cereal, pulses, millets and grasses. It is operated by both male and female.

\subsection{2. $\quad$ Sika (Knife)}

A Sika (knife) is a cutting tool and it is small as well as handy. The handle of the knife is made of wood and the working area is made of iron (Fig.20.). It is used in harvesting operation. Its handle is of almost 20 $\mathrm{cm}$ height, working area has $20 \mathrm{~cm}$ length and breadth of $3 \mathrm{~cm}$. It is operated by both male and female.

\subsubsection{Sika-gobda (Cleaver)}

A Sika-gobda (cleaver) is a big knife and the handle as well as the working area is made of iron (Fig.21.). It is used in harvesting operation, especially for cutting out sugar cane plant etc. Its handle is of $15 \mathrm{~cm}$ in height; working area has $25 \mathrm{~cm}$ length and $8 \mathrm{~cm}$ width and is use by both male and female.

\section{6. $\quad$ Post-Harvesting Tools And Technology}

The Bodos are using many post-harvesting tools and technology for their convenience, such as:

\subsubsection{Baukha}

Baukha is made of bamboo stick with pointed ends (Fig.22.). It is used for the purpose of carrying bundles of paddy from the cultivable land to the house or till the bullock cart. Six to eight bundles of paddy can be carried with the help of baukha at a time. It is about $120-130 \mathrm{~cm}$ in length and breadth of $3 \mathrm{~cm}$. This work is mainly carried out by men.

\subsubsection{Hukhen (Grain separator)}

Hukhen (grain separator) is made of bamboo (Fig.23.) and it is used in post-harvesting operation. The wheat and other grains, after drying are threshed with the help of oxen and the farmers after threshing with the help of hukhen shake the wheat or other grains materials forcibly so that the threshed materials and the grains are separated. It is operated by both male and female and it helps in separating the threshed materials and grains making the winnowing operation easier. Farmers can use this tool easily by standing straight and not bending and it is of about $240 \mathrm{~cm}$ in length and $3 \mathrm{~cm}$ in breadth.

\subsubsection{Royna}

Royna is a post-harvesting agricultural tool of the Bodos. It is an implement for scooping or gathering paddy and also used for the purpose of overturning paddy while drying it. Both the handle which is very long and the working place resembles a half circle are made of wood (Fig.24). Handle is of $170 \mathrm{~cm}$, working area is of $55-60 \mathrm{~cm}$ length and breadth is of $25 \mathrm{~cm}$ and it can be operated by both male and female workers.

\subsubsection{Sandanga (Sieve)}

Sandanga (sieve) is a bamboo-woven plate or screen with border area made also of bamboo tied to the working area with the help or metal wire or raiding (wild leaf used for tying) (Fig.25.). It is used in separating different kinds of grains from threshed materials. Both the length and the breadth is about $75 \mathrm{~cm}$ and mostly it is used by female.

\subsubsection{Songrai (Winnower)}

Songrai (winnower) is a round bamboo tightly woven plate used for winnowing the grain and separating grain from husk (Fig.26.). It involves throwing the mixture into air so that the wind blows away the 
lighter husk, while the heavier grains fall back down for recovery or it involves fanning the winnower over the mixture so that the wind blows the lighter husk, while the heavier grains fall back down for recovery. Its length and breadth is almost $75 \mathrm{~cm}$ and women workers mostly operate it.

\subsubsection{Khada ( Basket made of bamboo)}

Khada is made up of knotted bamboo stick and it is used for carrying grains of cereals, pulses etc. This bamboo made basket is plastered by cow dung so that grains or pulses do not fall out from the basket (Fig.27.). Length of the Khada measures $38 \mathrm{~cm}$ in length and $38 \mathrm{~cm}$ in breadth. It is operated by both male and female workers.

\subsubsection{Duli ( Grain store)}

Duli is made of knotted split bamboo, knotted in form of a large basket where the working area is tied to the border, made of bamboo stick with the help of metal wire or raiding and the external part of the duli is plastered with cow dung cake so that the grain does not fall outside (Fig.28.). Height of smaller kind of duli measures about $88 \mathrm{~cm}$ and the bigger ones measures almost 6-7 feet in height with $100-110 \mathrm{~cm}$ in breadth.

\subsubsection{Sandri ( Smaller kind of sieve)}

Sandri is a smaller kind of sieve used for the separation of different kinds of grain for elimination of a lien material using a woven screen such a mesh or net made of split knotted bamboo where the working area is tied to the border made of bamboo with the help of metal wire or raiding (wild leaf used for tying) (Fig.29.). It is generally operated by female worker.

\subsubsection{Dingkhi (Grinder)}

Dingkhi is grain grinder and it is made of wood and with its working area made of iron, it is like a sea saw where the user needs to place her leg at the bottom up and down so that the upper portion of the grinder hits the grains placed at the hole especially made for the purpose of grinding (Fig.30.). It is about $150-155 \mathrm{~cm}$ in length and is generally operated by women workers.

\subsubsection{Khasa (Rice Store basket)}

Khasa is a rice store basket; it is a kind of pot but bigger in size and it is made of cane and knotted bamboo stick (Fig.31.). It is almost $50 \mathrm{~cm}$ in both height and in breadth.

\subsubsection{Gan/Gaihen and Ual/Ural (Milling Tools)}

Ural and gaihen are used for the purpose of milling, leaf extract preparation, etc. Both ural and gaihen are made of wood and the gaihen (handle) though made of wood, the working area is made up of iron (Fig.32.). The length of the gaihen measures approximately $144 \mathrm{~cm}$ and $5.5 \mathrm{~cm}$ in breadth and it is generally operated by women workers.

\subsubsection{Don (Bamboo Pan)}

Don (bamboo pan) is made of knotted bamboo split and is used for collecting grains, rice, plant products and spreading of seeds (Fig.33.) Handling and transportation of grains and other products becomes easier and quicker with the help of this tools. The length of the don measures almost $20 \mathrm{~cm}$ in length and 25-30 $\mathrm{cm}$ in breadth. It is operated by both men and women.

\subsection{Measuring Tools And Technology}

The traditional tools and technology of the Bodos for the purpose of measurement are, such as:

\subsubsection{Phalla (Weighing Tool)}

Phalla is a weight measuring tool and it is round in shape, made of closely knotted split bamboo. The two round shape measuring plates are tied to a bamboo stick at both the ends with the help of ropes made of jute and another rope is tied to the middle of the bamboo stick, so that people can hold the rope at the middle of the bamboo stick and balance the phalla for the purpose of measuring grains with the help of weight units (Fig.34.). The length of the handle of phalla measures $15-20 \mathrm{~cm}$ in length and it can be operated by both male and female.

\subsubsection{Nareal Koltha (Coconut Cover)}

The Bodos used cleaned coconut cover for the purpose of measuring the grains of cereals, pulses and oilseeds (Fig.35.) in the past. It helped in measuring grains without taking the help of weight units and can be handled easily. And the height and the breadth of a nareal koltha is 3 and $4 \mathrm{~cm}$ respectively. 


\subsubsection{Kurai Kowrai}

The Bodos used kurai kowrai (bowl) made of kowrai for the purpose of measuring the grains of cereals, pulses and oilseeds in the past and it can be handled so easily in measuring grains without taking the help of weight units (Fig. 36). It measured $10 \mathrm{~cm}$ in both height and breadth.

\subsubsection{Kurai Gubai}

The Bodos from sound financial background also used kurai gubai (bronze made bowl) for measuring the grains of cereals, pulses and oilseeds (Fig.37.). It helps in measuring grains of cereals easily without the help of weight units and it measures $3.5 \mathrm{~cm}$ in height and $4.5 \mathrm{~cm}$ in breadth.

\subsection{Transportation Tools And Technology}

\subsubsection{Mosow Gari (Bullock Cart)}

Bullock cart is made of wood and bamboo and it as a source of transportation was developed long time ago to help farmers for cheap and simple transportation, it is widely used even today by the Bodo community. The two wheels of the bullock cart is also made of wood but this days instead of wooden wheels, modern tiers are also used (Fig.38.) Bullock cart is drawn by a pair of oxen and its main work is to carry paddy from the paddy field to the owner's house and also to carry passengers or a load.

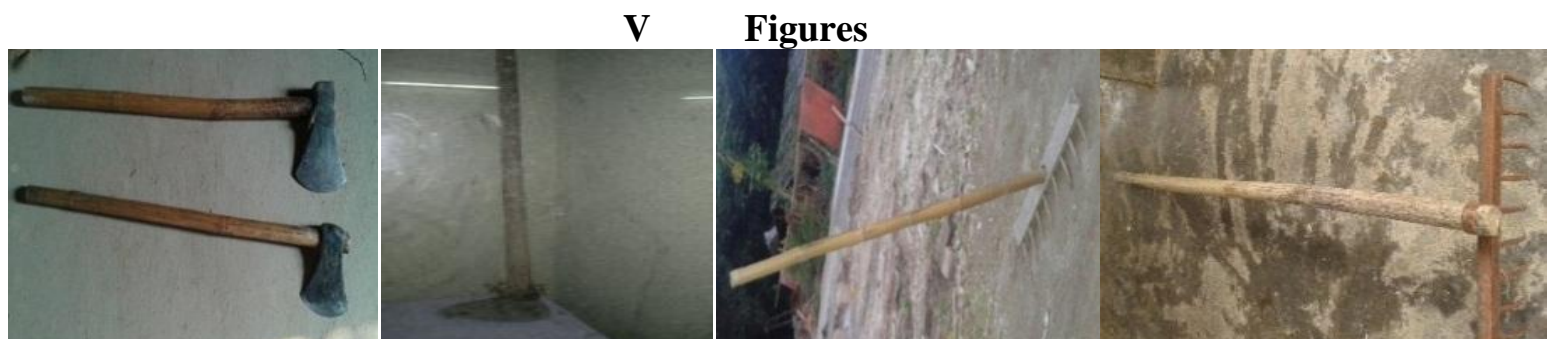
Fig.1. Ruwa
Fig. 2. Kodhal
Fig. 3. Dangur/Hasni
Fig. 4. Lohani Dangur/Hasni
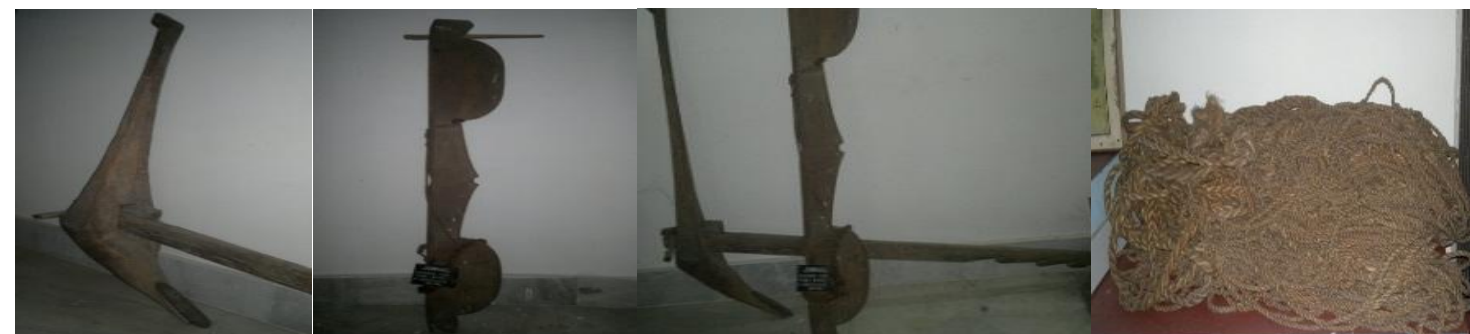

Fig. 5. Nangal with Pal Fig. 6. Jungal

Fig.7. Dilagaon

Fig. 8. Lengra dirun

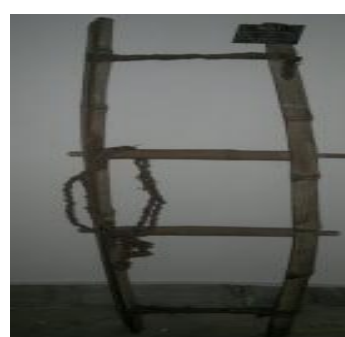

Fig. 9. $M w i$

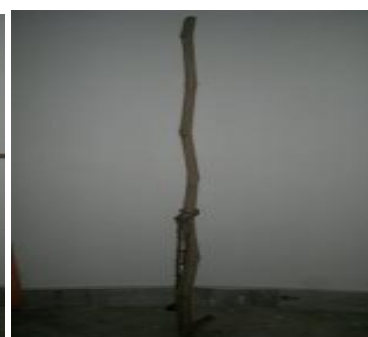

Fig. 10. Mwi Dangur

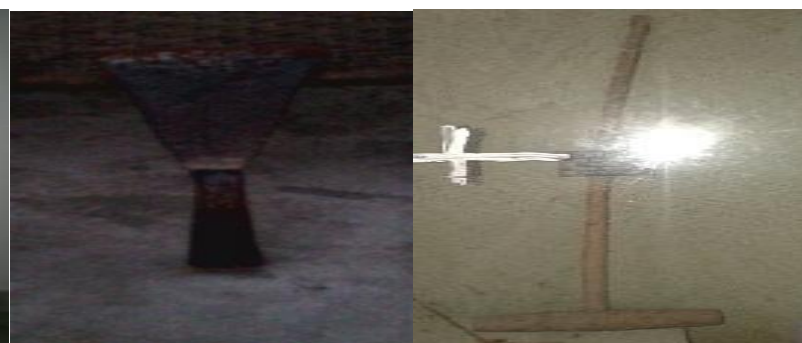

Fig.11. Khonta
Fig. 12. Gandri/ Dangan

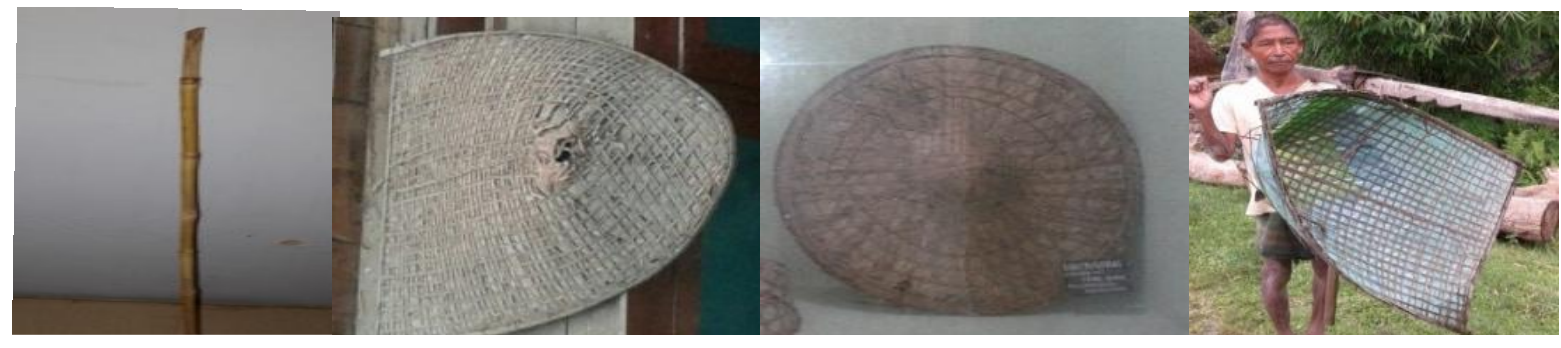


The Traditional Agricultural Tools and Technology used by the Bodos.

Fig. 13. Lauthi

Fig. 14. Muphur Kopri Fig. 15. Khopri Gubai

Fig. 16. Plasticni Khopri

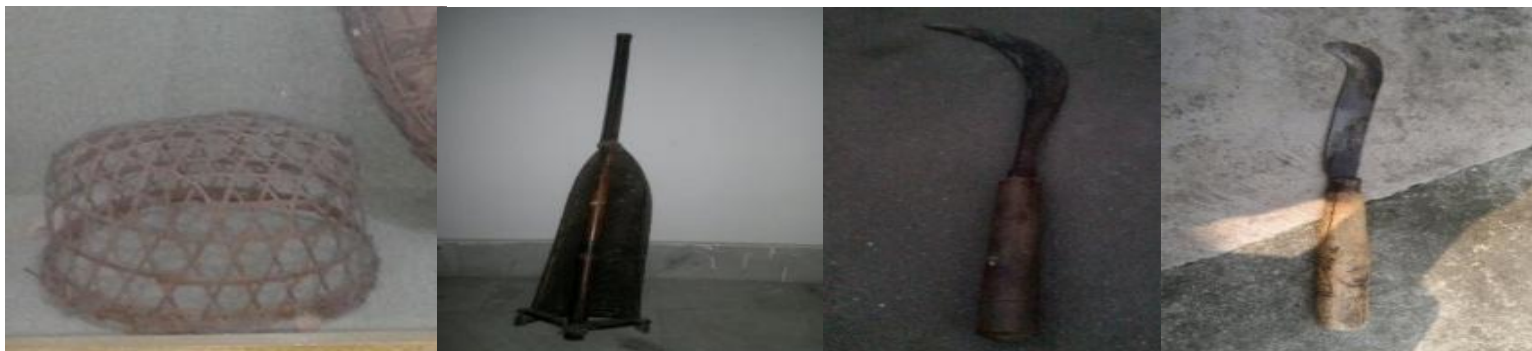

Fig. 17. Muka

Fig.18. Chilli

Fig. 19. Khasi

Fig. 20. Sikha

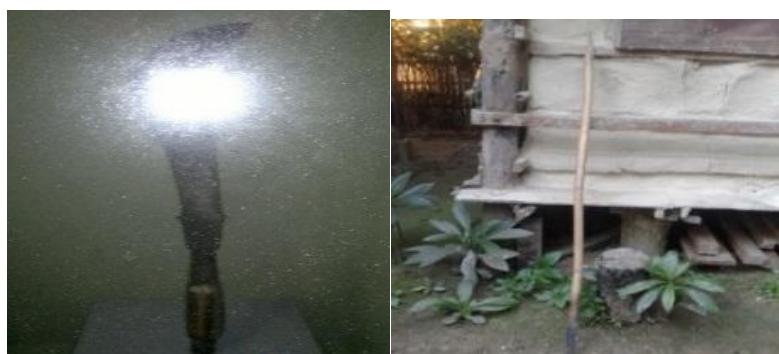

Fig. 21. Sika-Gobda
Fig. 22. Baukha

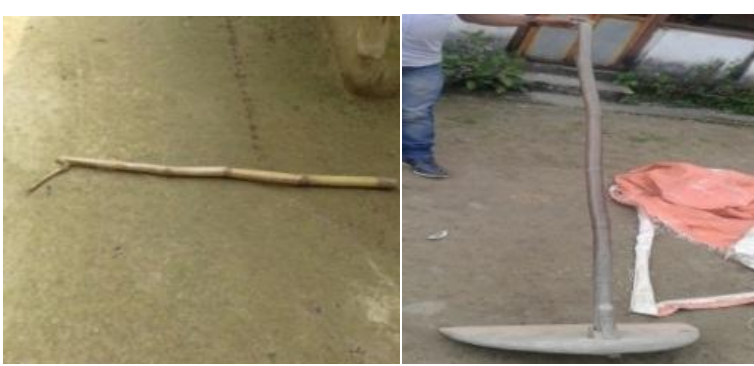

Fig.23. HukhenFig.
Fig.24. Royna

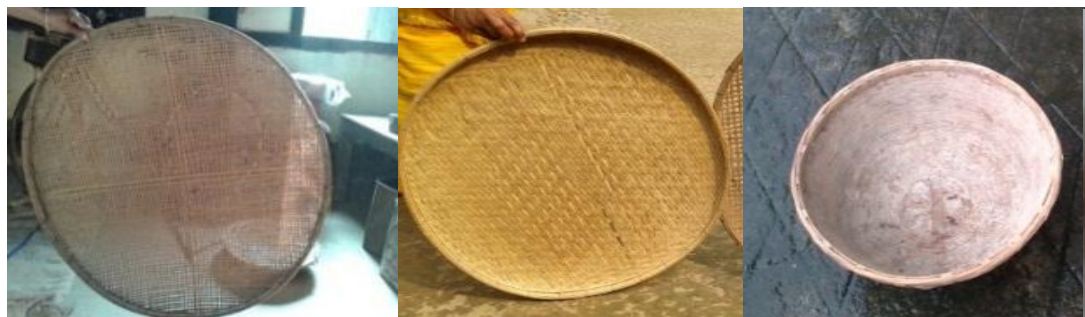

Fig. 25. Sandanga
Fig. 26. Songrai

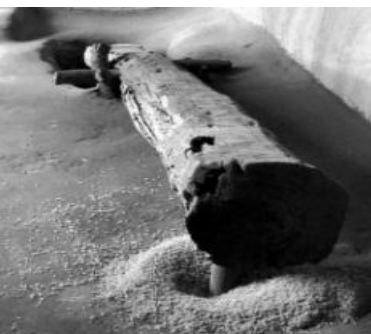

Fig. 30. Dingkhi
Fig. 27. Khada

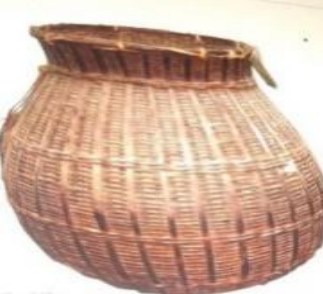

Fig.31. Khasa

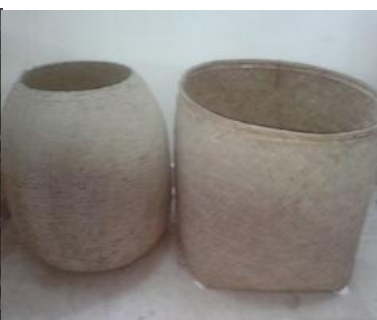

Fig. 28. Duli

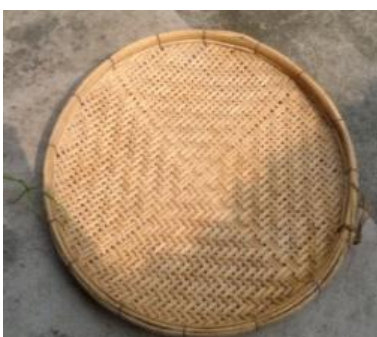

Fig. 29. Sandri

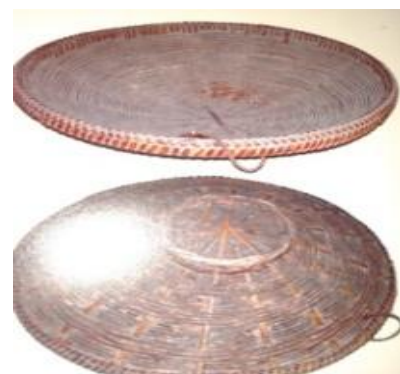

Fig. 32. DonFig.

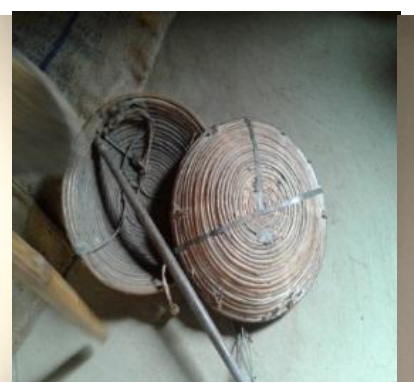

34. PhallaFig.

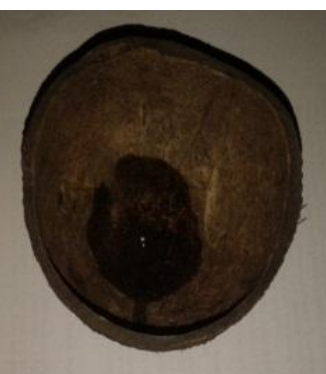

35. Naringkol Koltha

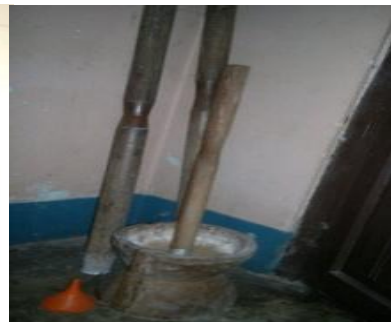

Fig.33. Gahen/Ural

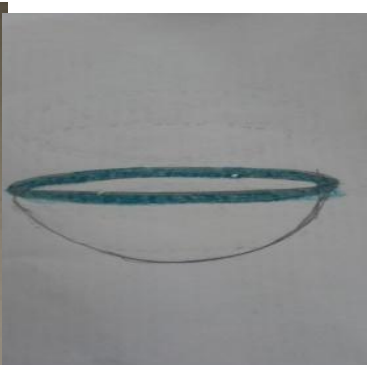

Fig. 36. Kurai Gowrai 


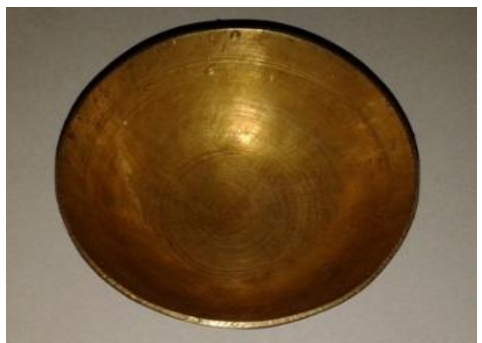

Fig. 37. KuraiGubai

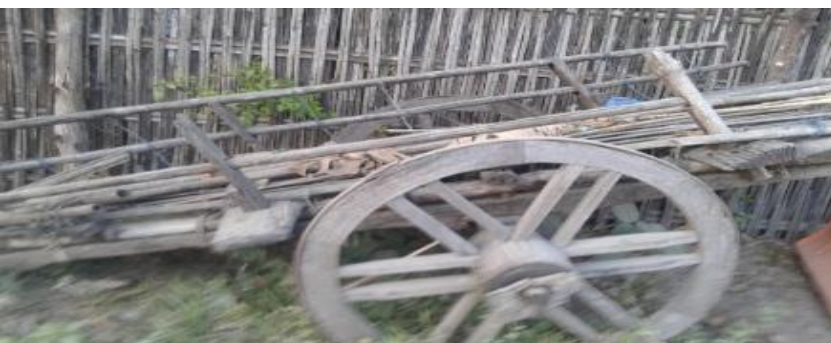

Fig.38. Mosow Gari

\section{Conclusion}

The traditional agricultural tools and technology of the Bodos are suitable since these tools and technology are easy to make, use, economical, feasible and sustainable. These tools can be transported easily from one region to another. The age old traditional agricultural tools and technology are though mostly still in used but at present along with some modern tools and technology, which with proper designs can be used to standardize these traditional tools and technology according to the economy of rural poor which would help in popularizing these tools and technology further. And thus it becomes important to document and preserve these age old traditional agricultural tools and technology in great interest, before these tools and technology completely extinct.

\section{Acknowledgements}

We would like to extend our thanks to Kokrajhar district Museum and Rajabari Museum, Coch Behar, West Bengal for providing us valuable information regarding traditional agricultural tools and technology of the Bodos. We want to extend our thanks to Janaram Borgoyari (Simbargaon), Bhanu Rani Brahma (Gossaigaon), Parameswar Brahma (Gossaigaon), Alaka Narzary (Tipkai), Someswar Narzary (Tipkai), Nandeswar Daimari (Jhakragaon), and Sachindra Nath Suba (Pacham Satali) for providing relevant information for this paper. We also want to extend our thanks to Dersin Daimari for assisting us to the field. Lastly we would like to extend our gratitude to Almighty God for giving us strength and guiding us throughout this paper work.

\section{References}

[1] Sekhar Brahma, Religion of the Boros and their Socio-Cultural Transition (Guwahati, DVS Publishers, 2011) 7-8.

[2] Suniti Kumer Chatterji, Kirata Jana Kriti (Kolkata, The Asiatic Society, 2011) 45-46.

[3] B. N. Bordoloi, G. C. Sharma Thakur, M. C. Saikia, Tribes of Assam (Part-I) (Guwahati, Tribal Research Institute, 1987 ) 3.

[4] Paresh Bhuyan, Folk Art \& Culture of Bodo- Kachari and Rabha Tribes of Assam ( Guwahati, Bodo Sahitya Sabha, 2015 ) 17.

[5] C. Karthikeyan, D. Veeraragavathatham, D. Karpagam \& S Ayisha Firdouse, Traditional tools in agricultural practices, Division of Agricultural Extension, Indian Journal of Traditional Knowledge, Vol.8(2), April 2009, .212-217.

[6] A. S. Elzubeir, Traditional agricultural tools and implements used in Sudan, International Journal of AgriScience, Vol.4 (2), February 2014, 140-146.

[7] Srimati Bijaya Laxmi Brahma Chaudhury, Bodo (Kacharis) at a glance, Bongaigaon, Tribal Cultural Institute, $1993,6$.

[8] Rev. Sidney Endle, The Kacharis, Guwahati, Bina Library, 2007, 13. 